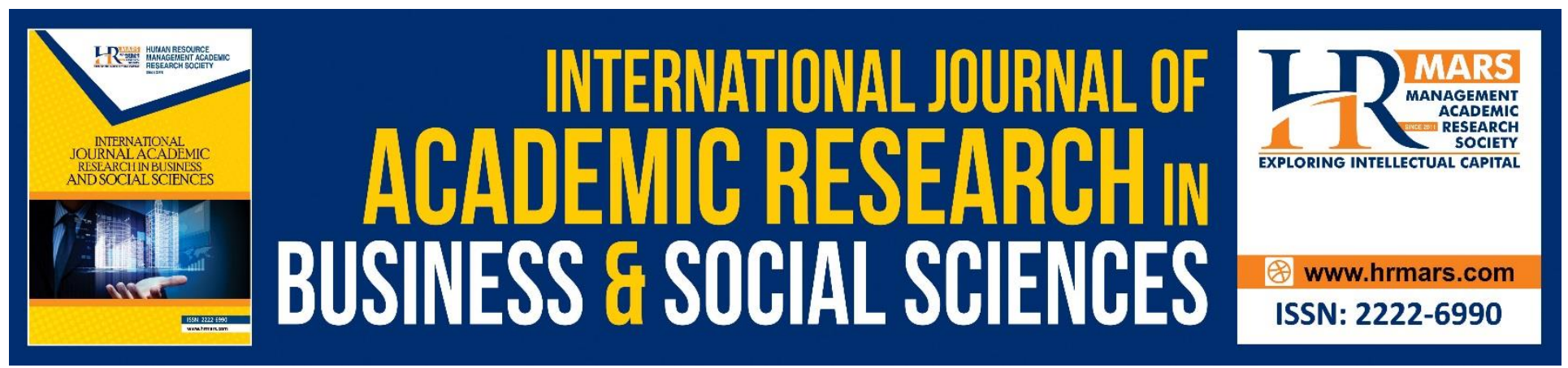

\title{
The Influence of Personality Traits on Irrational Beliefs in Malaysian Teachers
}

Mastura Mahfar, Aslan Amat Senin, Chua Yong and Faizah Abd. Ghani

To Link this Article: http://dx.doi.org/10.6007/IJARBSS/v8-i8/4632

DOI: $\quad 10.6007 /$ IJARBSS/v8-i8/4632

Received: 21 June 2018, Revised: 17 July 2018, Accepted: 30 July 2018

Published Online: 08 August 2018

In-Text Citation: (Mahfar, Senin, Yong, \& Ghani, 2018)

To Cite this Article: Mahfar, M., Senin, A. A., Yong, C., \& Ghani, F. A. (2018). The Influence of Personality Traits on Irrational Beliefs in Malaysian Teachers. International Journal of Academic Research in Business and Social Sciences, 8(8), 775-789.

Copyright: (C) 2018 The Author(s)

Published by Human Resource Management Academic Research Society (www.hrmars.com)

This article is published under the Creative Commons Attribution (CC BY 4.0) license. Anyone may reproduce, distribute, translate and create derivative works of this article (for both commercial and non-commercial purposes), subject to full attribution to the original publication and authors. The full terms of this license may be seen at: http://creativecommons.org/licences/by/4.0/legalcode

Vol. 8, No. 8, August 2018, Pg. 775 - 789

Full Terms \& Conditions of access and use can be found at http://hrmars.com/index.php/pages/detail/publication-ethics 


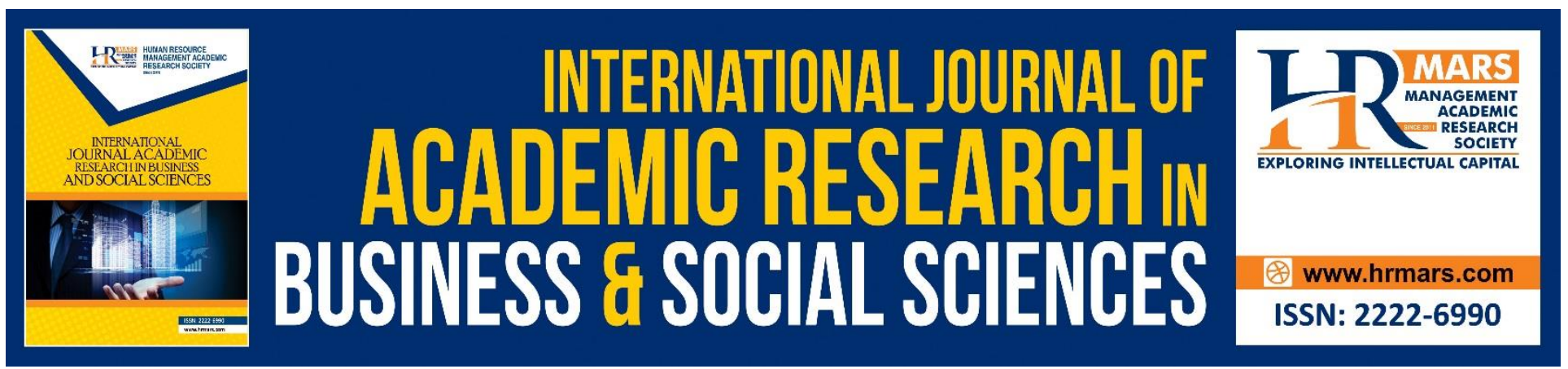

\title{
The Influence of Personality Traits on Irrational Beliefs in Malaysian Teachers
}

\author{
Mastura Mahfar ${ }^{1 *}$, Aslan Amat Senin², Chua Yong and Faizah Abd. \\ Ghani ${ }^{4}$ \\ $1^{*}, 3$ School of Human Resource Development and Psychology, \\ Universiti Teknologi Malaysia, 81310 Skudai, Johor, Malaysia \\ ${ }^{2}$ Azman Hashim International Business School, \\ Universiti Teknologi Malaysia, 81310 Skudai, Johor, Malaysia \\ ${ }^{4}$ School of Education, \\ Universiti Teknologi Malaysia, 81310 Skudai, Johor, Malaysia
}

\begin{abstract}
Personality has been identified as an influential variable associated with irrational beliefs. However, only a few studies have examined its prediction on irrationality. This study was conducted to develop a better understanding of how specific personality traits (openness to experience, conscientiousness, extraversion, agreeableness, and neuroticism) serve as predictors of irrational beliefs in Malaysian teachers. A Big Five Inventory (BFI) and Teacher Irrational Beliefs (TIB) were employed to evaluate 132 primary school teachers from 16 government-funded schools in the district of Muar, Malaysia. In general, the correlation results showed that all the personality traits examined significantly correlated with irrational beliefs. The multiple regression results indicated that openness to experience and extraversion had a significantly negative influence on the irrational beliefs of the teachers while neuroticism showed not only a significant positive influence on the teachers' irrational beliefs but it was also found to be a strong predictor of their irrationality. The findings highlight the importance to take personality traits into account as potential vulnerability factors of irrational beliefs.
\end{abstract}

Keywords: Big Five Personality Traits, Irrational Beliefs, Teacher Stress, REBT.

\section{Introduction}

Irrational beliefs which are the focus of Rational Emotive Behaviour Therapy (REBT) was previously known as the Rational Emotive Therapy (RET) and it was initially developed by Albert Ellis in the 1950's. REBT posits that people always mistakenly blame external events for their unhappiness (Ellis, 1994). In the face of adversity, it is the belief about the situation but not the situation itself that leads to emotional disturbances (Ellis, 1994; Turner \& Barker, 2015). In REBT, beliefs are at the core of 
individuals' emotions and behaviours (Dryden and Branch, 2008). Beliefs can either be rational and healthy, or it can also be irrational and unhealthy (Choudhury, 2013; Vernon, 2004; Dryden, 1999).

Beliefs are rational when they are logical, flexible or non-extreme, consistent with reality, and largely helpful to the individual in pursuing his basic goals and purposes. On the other hand, irrational beliefs are the core of psychological problems, and they are essentially rigid or extreme in nature, inconsistent with reality, illogical, and largely detrimental to the individual in pursuing his basic goals and purposes (Dryden \& Branch, 2008). It has been argued that undesirable emotional and behavioural consequences are largely due to irrational thoughts or beliefs (Ellis, 1994; Dryden, 1999).

In line with REBT's hypothesis, a number of studies have offered the empirical evidence on the association between irrational beliefs and dysfunctional emotions (Brown, Dowd, \& Freeman, 2010) as well as the correlation between irrational beliefs and maladaptive behaviours (Szentagotai \& Jones, 2010; Turner \& Barker, 2015). According to David, Montgomery, Macavie, Bovbjerg, Macavie, and Bovbjerg (2005) and Dryden (1999), there are four main categories of irrational beliefs which are demandingness, awfulizing or catastrophizing, global evaluation or self-downing and low frustration tolerance.

In the context of the teaching profession, researches have also shown the relationship between irrational beliefs and the stress suffered by teachers. A study by Bernard (2016) on the relationship between irrational beliefs and stress among primary and secondary school teachers in Australia revealed that irrational beliefs had been associated with teachers' stress. Such findings are not only prevalent in studies involving Western subjects, but also in the findings based on Malaysian studies. Studies conducted by Said (2013) and Khoo (2015) indicated the correlation between irrational beliefs and teachers stress. The findings indicated that in Malaysia, the level of stress among teachers is steadily increasing. Teachers have to carry out various tasks apart from teaching, including marking homework, handling student discipline problem, dealing with parents and managing paperwork, causing them considerable stress. Despite this, the emotional issues experienced by the teachers have not been given due consideration (Samad, Hashim, Moin, \& Abdullah, 2010; Khoo, 2015).

The finding in a study conducted by Khoo (2015) reported that 23.6 percent of teachers reported a high level of irrational belief. As a result, the level of teachers' stress varies with the degree of endorsement of irrational beliefs which confirms the REBT's hypothesis (Zingle \& Anderson, 1990; Bora, Bernard, Trip, Decsei-Radu, \& Chereji, 2009).

Based on the arguments presented in REBT, the pressures caused by a sense of 'demandingness' should be given due attention because it can lead to stress (Khoo, 2015). Demandingness refers to any rigid ideas that individuals hold about how things absolutely must or must not be (Dryden, 2006). For instances, "I must be a good teacher" or "Others must treat me fairly". Teachers with irrational beliefs such as 'demandingness' may believe that they should have perfect control over their class and their students must be able to achieve good performance (Meehan, 2011). Meanwhile, teachers with rational beliefs understood that in reality, nothing is perfect and they attempted their best in controlling the class and helping their students' learning process of (Meehan, 2011).

Meanwhile, awfulizing is extreme ideas that individuals hold about how bad it is when their demands are not met (Dryden, 2006). For example, "It is awful when I'm not approved by others". Another type of irrational beliefs is low frustration tolerance which refers to any extreme ideas that individuals hold about the tolerability of events when their demands are not met (Dryden, 2006). For example, "I can't stand if you don't treat me fairly". Global evaluation is extreme ideas that individuals 
hold about self, others, and/or the world by giving a single global rating when they do not get what they demand. For example, "I'm a worthless teacher if I'm not approved" or "My employer is a bad person if he/she does not treat me fairly". Thus, individuals with high levels of irrational beliefs are more likely to develop unhealthy emotions if their demands are not met (Marić, 2000).

Based on the evidence put forward, the importance of investigating the teachers' irrational beliefs in a more comprehensively manner is needed as previous studies have proven its association with emotional disturbances. Indeed, our search on REBT literature in the Web of Science database (using the keywords "rational emotive", "rational-emotive" and REBT, within period 1990-2018) found 310 entries. A closer look at the list, however, found that published articles focused more on the efficacy of the REBT programme. Currently, there are limited studies on the factors explaining the irrational beliefs itself, which is the key aspect of REBT theory.

With regard to the predictors of irrational beliefs, there are some early empirical evidence which relate personality with irrational beliefs, for example studies conducted by Jones (1968), Gorman and Simon (1977), Forman and Forman (1978), Wicker, Richardson and Lambert (1985), and Zurawski and Smith (1987). Later studies investigated the relationships between personality traits and irrational beliefs applying more parsimonious Big Five model (see Table 1). The Five Factor Model (FFM) or better known as the Big Five model consists of openness to experience, conscientiousness, extraversion, agreeableness, and neuroticism, which are often represented by the OCEAN acronyms (McCrae \& Costa, 1987, 2008; Samar, Walton, \& McDermut, 2013).

The Big Five Personality theory has been widely used in different cultures and contexts and renowned for its ability to predict psychological outcomes (Costa \& McCrae, 1992; McCrae \& John, 1992; McCrae \& Costa, 1997). According to the theory, people with a high score on the openness to experience is likely to be more imaginative, original, insightful and intellectual. They also appear to show a tendency to love learning. In comparison, people with higher conscientiousness tend to show higher levels of self-discipline. Subsequently, this trait causes them to be more ambitious and persistent in achieving their goals.

On the other hand, people with a high score on extraversion are more inclined to be more sociable, assertive and talkative while those who achieve a high score on the agreeableness factor tend to be more sympathetic, affectionate and sensitive to the needs of others. Finally, people who score higher on the neuroticism trait are more likely to show higher levels of emotional instability and negative emotions. They tend to display a high level of anxiety, impulsiveness, and depression. (Costa \& McCrae, 1992; McCrae \& John, 1992; McCrae \& Costa, 1997). Hence, Samar et al. (2013) argued that the Big Five personality model is appropriate for studying personality traits among adults.

The review of previous research finds five published empirical studies on the link between the Big Five personality traits and irrational beliefs (as summarised in Table 1). Davies (2006) asserts that neuroticism correlates positively with irrational beliefs, based on a sample of UK university students. $\mathrm{He}$ also observes that openness to experience and also conscientiousness traits correlate negatively with irrational beliefs. However, no relationship is found between agreeableness and irrational beliefs in this study.

Sava (2009), in a study involving Romanian undergraduates, indicates that there is a positive relationship between irrational beliefs and neuroticism and a negative relationship between irrational beliefs and agreeableness. Similar results are reported by Spörrle, Strobel and Tumasjan (2010), in their study based on a German sample which observes that neuroticism is positively related to irrational beliefs. Apart from that, openness to experience and agreeableness are reported to be negatively correlated with irrational beliefs in this study. 
Meanwhile, Ghumman and Shoaib (2013) conducted a research with Pakistani respondents to study the linkage between personality traits with irrational beliefs of adults. The study involved 516 undergraduate and postgraduate respondents with the mean age of 18-25. The results revealed a significant and negative relationship between openness to experience, conscientiousness, agreeableness, and extraversions with irrational beliefs. Meanwhile, neuroticism showed a significant and positive relationship with irrational beliefs.

In the US, a study by Samar et al. (2013) also examined the possibility of personality traits in predicting rational and irrational beliefs of individuals. The respondents were 125 young teens and 117 clinical samples. The result showed irrational beliefs have a positive relationship with neuroticism. Meanwhile, irrational beliefs are found to be negatively related to openness to experience, conscientiousness, agreeableness, and extraversion. In general, these studies consistently found the positive association between neuroticism and irrational beliefs. There were consistent findings of non-association between extraversion and irrational beliefs. Some studies indicated a negative association between openness to experience and agreeableness with irrational beliefs.

However, the findings of previous studies were limited because most of them reported only correlational results (Davies, 2006; Sava, 2009; Spörrle et al., 2010; Ghumman \& Shoaib, 2013), as well as being conducted in student settings (Davies, 2006; Sava, 2009; Samar et al., 2013; Ghumman and Shoaib, 2013) as shown in Table 1. Additonally, the previous studies had conflicting results regarding the association between conscientiousness and irrational beliefs.

Thus, it is crucial to fully understand irrational beliefs, mainly in terms of exploring the links between personality traits and irrational beliefs in a school setting, specifically in relation to Malaysian teachers. Therefore, the purpose of this study is to identify whether personality is a predictor of teachers' irrational beliefs. 
INTERNATIONAL JOURNAL OF ACADEMIC RESEARCH IN BUSINESS AND SOCIAL SCIENCES Vol. 8, No. 8, August 2018, E-ISSN: 2222-6990 C 2018 HRMARS

Table 1. Big Five Personality Traits and Irrational Beliefs Correlation Results in Past Studies

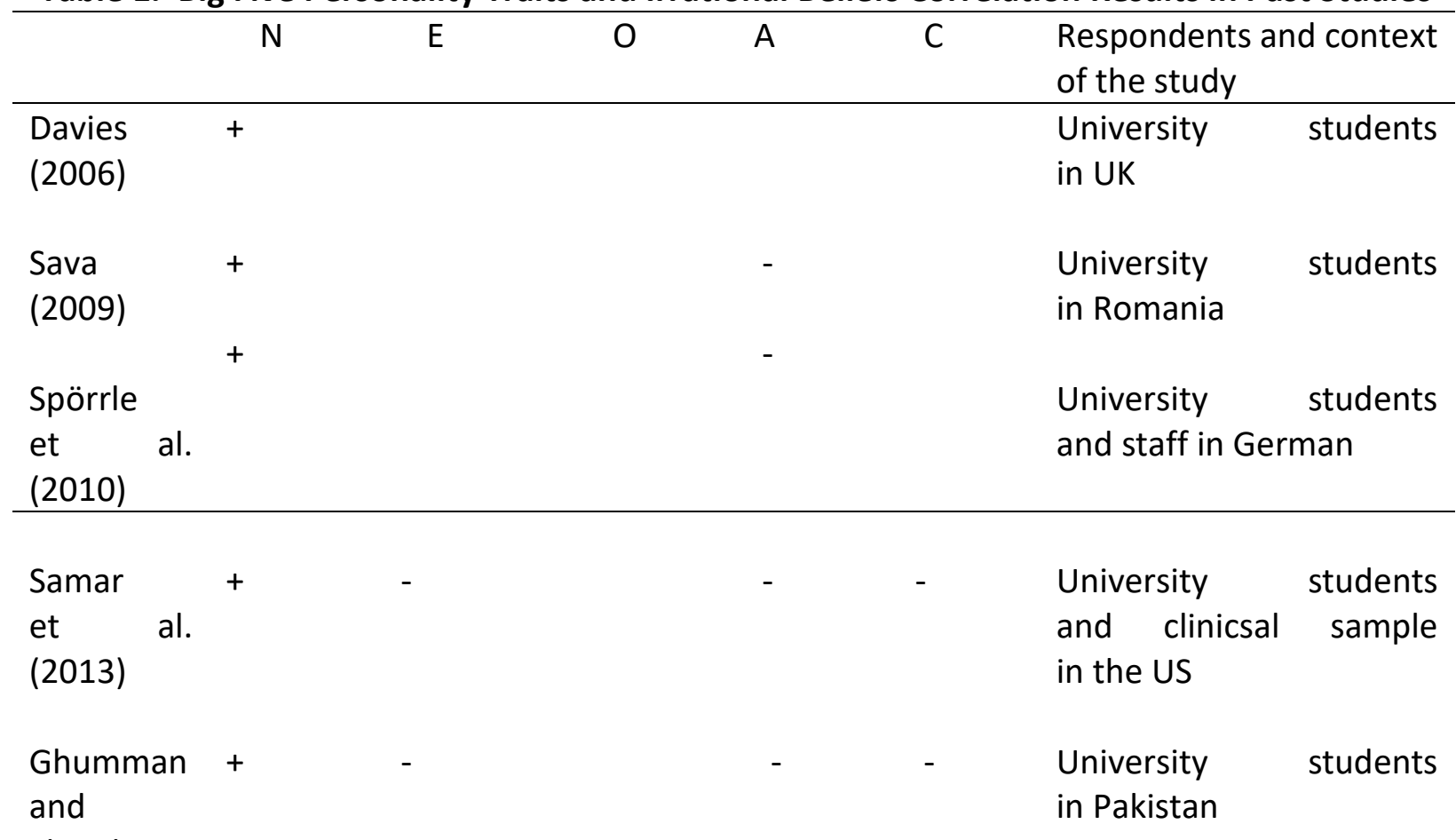

Shoaib

(2013)

$\mathrm{N}=$ Neuroticism, $\quad \mathrm{E}=$ Extraversion, $\mathrm{O}=$ Openness to experience, $\mathrm{A}=$ Agreeableness,
$\mathrm{C}=$ Conscientiousness
+ significant positive correlation; - significant negative correlation

The motivation behind the present study is the high level of stress reported among school teachers. Therefore, understanding the nature and antecedent of irrational beliefs which are closely associated with stress may help to address the problem. Furthermore, it was claimed that teachers with irrational beliefs would respond negatively to their students, thus hindering positive relationships with their students and the potential for classroom success (Warren, 2013). Irrational beliefs will also lead to negative emotions, such as anger and depression (Ellis, 1962, 1994). These emotional disturbances would reduce the teachers' job performance and enjoyment of life (Warren, 2013). Considering the evidence that irrational beliefs contribute to distress, research examining personality traits as predictors of irrational beliefs, especially in the context of teachers in Malaysia, is timely.

Hence, the aim of the present study is to extend the existing literature using well-known Big Five personality traits model to determine whether personality traits predict irrational beliefs among primary school teachers in Johor. The irrational beliefs are treated as a dependent variable. The independent variables are presented by the Big Five personality traits. Five hypotheses have been tested by employing multiple linear regression (MLR) method which posited that:

$H_{1}$ : Openness to experience has a significantly negative influence on irrational beliefs.

$\mathrm{H}_{2 \text { : }}$ Conscientiousness has a significantly negative influence on irrational beliefs. 
INTERNATIONAL JOURNAL OF ACADEMIC RESEARCH IN BUSINESS AND SOCIAL SCIENCES

Vol. 8, No. 8, August 2018, E-ISSN: 2222-6990 @ 2018 HRMARS

$H_{3}$ : Extraversion has a significantly negative influence on irrational beliefs.

$H_{4}$ : Agreeableness has a significantly negative influence on irrational beliefs.

$\mathrm{H}_{5}$ : Neuroticism has a significantly positive influence on irrational beliefs.

\section{Method}

\section{Participants}

Participants in this study were 132 primary school teachers (112 females, 20 males) in the age range of 26 to 55 years. The respondents were selected through stratified random sampling from 250 primary school teachers in 16 government-funded Chinese schools located in the district of Muar, Malaysia.

\section{Measures}

In this study, a set of questionnaire was administered to each respondent. Each questionnaire includes demographic questions and scales to measure personality traits and irrational beliefs.

The Big Five Inventory (BFI). The BFI (John \& Srivastava, 1999) is used to measure the personality traits of the respondents. A BFI consists of 44 items which are designed to measure specific personality traits, namely openness to experience, conscientiousness, extraversion, agreeableness, and neuroticism. An example of how these items are presented is, "Tends to be disorganized". In addition to that, the BFI items are rated on a 5-point scale ranging from strongly disagree (1) to strongly agree (5).

The evaluation of BFI indicates that the content is capable of measuring the Big Five personality traits of individuals (Eswaran et al., 2011). Moreover, the reliability test for the BFI was found to be within an acceptable level.

The BFI has been shown to have adequate internal consistency on all the five personality traits examined in the present study with Cronbach's alphas of .71 for the openness to experience dimension, .74 for the conscientiousness dimension, .74 for the extraversion dimension, .71 for the agreeableness, and .83 for the neuroticism.

The Teacher Irrational Beliefs (TIB). The TIB (Mahfar, 2015) was a 49-item questionnaire that was used to assess the irrational beliefs of the teachers. The TIB items were designed to measure four dimensions of irrational beliefs, namely demandingness, awfulizing, low frustration tolerance and global evaluation which were derived from the REBT approach. The four dimensions were also consistent with the suggestion by Dryden (1999) regarding the measurement of irrational beliefs of teachers. One of the items for this questionnaire is "I' $m$ a worthless teacher if I made a big mistake at my workplace". Items were presented using a 5-point scale $(1=$ strongly disagree to $5=$ strongly agree).

TIB has been used in the previous studies involving secondary school teachers and it exhibited good internal consistency (Said, 2013; Khoo, 2015). The content validity of the TIB has been supported through verification of experts' assessments to ascertain that the TIB content is capable of measuring the irrational beliefs variable. The Rasch model analysis from the Item Response Theory (IRT) using the Winstep software was employed to validate the measurement of a model (Bond \& Fox, 2008). The TIB's value of item reliability was .98, and the individual reliability coefficient was .74. The principal component analysis (PCA) which was used to analyse the dimensions of the TIB showed 
INTERNATIONAL JOURNAL OF ACADEMIC RESEARCH IN BUSINESS AND SOCIAL SCIENCES

Vol. 8, No. 8, August 2018, E-ISSN: 2222-6990 @ 2018 HRMARS

that the PCA returned an observed value of more than $40 \%$ variance, explained by measures which indicated that the TIB measured the stipulated dimensions.

The TIB had also been shown to have satisfactory internal consistency on all four dimensions in this study. Reliability analysis using Cronbach's alpha showed a high- reliability coefficient for the irrational beliefs ( $\alpha=.74$ ) with Cronbach's alphas of .82 for the demandingness, .71 for the awfulizing, .87 for the low frustration tolerance, and .71 for the global evaluation.

\section{Results}

\section{Initial Data Analysis}

The SPSS version 19 software was used to analyse the data. Table 2 illustrates the mean values (M) and standard deviation (SD) analysis of the Big Five personality traits of the entire sample of teachers. The mean scores obtained by the respondents ranged between 3.00 to 3.17 which are at a moderate level (2.34-3.67). Findings showed that the openness to experience $(\mathrm{M}=3.00, \mathrm{SD}=0.91)$ and conscientiousness $(M=3.00, S D=0.94)$ traits obtain the lowest mean whereas the highest mean value is neuroticism $(\mathrm{M}=3.17, \mathrm{SD}=0.82)$ as shown in Table 2 .

Table 2. Big Five Personality Traits ( $=132)$

\begin{tabular}{llll}
\hline & $\mathrm{M}$ & $\mathrm{SD}$ & Range \\
\hline Openness to experience & 3.00 & 0.91 & $2.34-3.67$ \\
Conscientiousness & 3.00 & 0.94 & $2.34-3.67$ \\
Extraversion & 3.06 & 0.74 & $2.34-3.67$ \\
Agreeableness & 3.03 & 0.98 & $2.34-3.67$ \\
Neuroticism & 3.17 & 0.82 & $2.34-3.67$ \\
\hline
\end{tabular}

Table 3 presents the mean and standard deviation for the sample teachers' levels of irrational beliefs. The mean scores obtained by respondents for the dimensions of irrational beliefs range from 2.87 to 3.07 which are considered to be at a moderate level (2.34-3.67). Out of these dimensions, the global evaluation $(M=2.87, S D=0.92)$ is the lowest while the dimension of low frustration tolerance $(M=$ $3.07, \mathrm{SD}=0.69$ ) obtains the highest mean.

Table 3. Teacher Irrational Beliefs ( $N=132)$

\begin{tabular}{llll}
\hline & $\mathrm{M}$ & $\mathrm{SD}$ & Range \\
\hline Demandingness & 2.98 & 0.75 & $2.34-3.67$ \\
Awfulizing & 3.05 & 0.88 & $2.34-3.67$ \\
Low frustration tolerance & 3.07 & 0.69 & $2.34-3.67$ \\
Global evaluation & 2.87 & 0.92 & $2.34-3.67$ \\
\hline Irrational Beliefs & 2.99 & 0.81 & $2.34-3.67$ \\
\hline
\end{tabular}

\section{Correlational Analysis}

Table 4 presents the correlations analysis between the Big Five personality traits and the irrational beliefs of the respondents. In general, the results indicate that personality traits such as openness to experience $(r=-0.36, p<.05)$, conscientiousness $(r=-0.25, p<.05)$, extraversion $(r=-0.30, p<.05)$, and agreeableness $(r=-0.18, p<.05)$ have a significant negative relationship with irrational beliefs. 
INTERNATIONAL JOURNAL OF ACADEMIC RESEARCH IN BUSINESS AND SOCIAL SCIENCES

Vol. 8, No. 8, August 2018, E-ISSN: 2222-6990 @ 2018 HRMARS

Neuroticism has been shown to have a significant positive relationship with irrational beliefs $(r=0.24$, p<.05).

Table 4. Correlations between the BFI and TIB Scores

\begin{tabular}{lllllll}
\hline & $\mathrm{I}$ & $\mathrm{II}$ & $\mathrm{III}$ & $\mathrm{IV}$ & $\mathrm{V}$ & $\mathrm{VI}$ \\
\hline Openness to experience & 1 & & & & & \\
Conscientiousness & $0.49^{*}$ & 1 & & & & \\
Extraversion & $0.56^{*}$ & $0.34^{*}$ & 1 & & & \\
Agreeableness & $0.44^{*}$ & $0.38^{*}$ & $0.47^{*}$ & 1 & & \\
Neuroticism & 0.09 & -0.06 & $0.32^{*}$ & $0.23^{*}$ & 1 & \\
Irrational beliefs & $-0.36^{*}$ & $-0.25^{*}$ & $-0.30^{*}$ & $-0.18^{*}$ & $0.24^{*}$ & 1 \\
\hline
\end{tabular}

* Correlation is significant at the .05 level

$\mathrm{I}$ = Openness to experience, $\mathrm{II}=$ Conscientiousness, III = Extraversion,

IV = Agreeableness, $\mathrm{V}=$ Neuroticism, $\mathrm{VI}=$ Irrational beliefs

\section{Multiple Regression Analysis}

Table 5 depicts the results of the hypotheses testing. The assumptions of multiple regression have been satisfied for all the hypotheses. Based on Table 5, hypotheses $H_{1}$ to $H_{5}$ are tested at the .05 significance level. The two dimensions of openness to experience $(B=-.217, p<.05)$, and extraversion $(b=-.276, p<.05)$ exert significant negative influence on irrational beliefs. The findings also confirmed that neuroticism $(B=.353, p<.05)$ has a positive influence on irrational beliefs.

However, the results indicate that there are no significant influence of two dimensions of conscientiousness $(B=-.012, p>.05)$ and agreeableness $(B=-.032, p>.05)$ on irrational beliefs of the respondents. Hence, the hypotheses in this study are only partially supported by $\mathrm{H}_{1}, \mathrm{H}_{3}$, and $\mathrm{H}_{5}$. The standardized regression coefficients reveal that neuroticism is a strong predictor of irrationality $(B=$ $.353, t=4.216, p<.05)$, followed by extraversion $(B=-.2760, t=-2.719, p<.05)$ and openness to experience $(B=-.217, t=-2.217, p<.05)$. Big Five personality traits are significantly contributed by 25.4 percent of the variance in irrational beliefs as explained by $R^{2}=0.254, F(8.592), \quad p<.05$. 
INTERNATIONAL JOURNAL OF ACADEMIC RESEARCH IN BUSINESS AND SOCIAL SCIENCES Vol. 8, No. 8, August 2018, E-ISSN: 2222-6990 @ 2018 HRMARS

Table 5. Summary of Regression Model for Big Five Personality Traits Predicting Irrationality

\begin{tabular}{lcccc}
\hline Model & $\mathrm{R}$ & $\mathrm{R}$ Square & $\begin{array}{l}\text { Adjusted } \\
\mathrm{R} \text { Square }\end{array}$ & Sig.F Change \\
\hline 1 & .504 & .254 & .225 & .000 \\
\hline
\end{tabular}

Coeefficients

\begin{tabular}{|c|c|c|c|c|c|}
\hline \multirow[t]{2}{*}{ Model } & \multicolumn{2}{|c|}{ Unstandardized Coefficients } & \multicolumn{3}{|l|}{$\begin{array}{l}\text { Standardized } \\
\text { Coefficients }\end{array}$} \\
\hline & B & Std. Error & Beta & $t$ & Sig \\
\hline (Constant) & 164.104 & 9.186 & & & \\
\hline $\begin{array}{l}\text { Openness to } \\
\text { Experience }\end{array}$ & -.569 & .268 & -.217 & -2.127 & $.035^{*}$ \\
\hline Conscientiousness & -.035 & .257 & -.012 & -.135 & .893 \\
\hline Extraversion & -.960 & .353 & -.276 & -2.719 & $.007^{*}$ \\
\hline Agreeableness & -.082 & .241 & -.032 & -.340 & .734 \\
\hline Neuroticism & 1.057 & .251 & .353 & 4.216 & $.000 *$ \\
\hline
\end{tabular}

Note: Significant level, ${ }^{*} p<.05$

\section{Discussion}

This study was undertaken to develop a better understanding of the influence of personality traits on irrational beliefs among Malaysian school teachers. The findings of this study suggest that certain personality traits such as openness to experience, extraversion, and neuroticism exert an influence on irrational beliefs.

In particular, the predicative positive relationship between neuroticism and irrational beliefs was consistently reported in previous studies was replicated in our study on Malaysian teachers. The finding was consistent with the findings of studies conducted by Davies (2006), Sava (2009), Spörrle et al., 2010, Ghumman and Shoaib (2013) and Samar et al. (2013). In addition, this study also indicated neuroticism's significant contribution to the irrational beliefs of teachers which was also found in a study conducted by Ghumman and Shoaib (2013).

This finding implied that neuroticism which was closely related to the negative emotions of individuals, such as the feeling of sadness, anxiety, anger, and embarrassment (Trouba, 2007) can influence an individual's way of thinking. Hence, teachers who had high emotional stability were more likely to be less prone to irrational beliefs. This finding was also consistent with the basic tenet of REBT where irrationality was associated with unhealthy emotions and psychological disturbances (Ellis, 1997).

The results also showed that openness to experience had a negative influence on irrational beliefs which was consistent with the findings of previous studies on the association between the Big Five personality traits and irrational beliefs (Davies, 2006; Spörrle et al., 2010; Samar et al., 2013). An increased openness to experience trait which reflected open-mindedness and creativity can be associated with an individual's low irrationality.

Similarly, it was also shown that extraversion had a significant negative influence on irrational beliefs. The present finding was consistent with previous findings of Ghumman and Shoaib (2013) and Samar et al. (2013). Psychological studies had reported that extrovert people have advantages in verbal skills (Dewaele \& Furnham, 1999). Instead of working alone, extrovert employees are more 
sociable, can easily interact and cooperate with others in the workplace (Vida, 2010) and they reevaluate problems in a positive way (Costa \& McCrae, 1995; Bakker et al., 2006). Such behaviour would lead them to think more rationally.

Interestingly, our findings did not show any association between agreeableness and irrational belief, which was contrary to the findings of the existing literature. This might be attributed to the context of the study and it needs further investigation. It is interesting to note the association between extraversion with irrational beliefs in this study despite the lack of evidence of such association in the previous studies. Again, this might be context specific and needs further investigation. There are inconsistencies in the literature regarding the association between the conscientiousness trait and irrationality. This study did not find any relation between the two variables.

Furthermore, the result showed that the Big Five personality traits contributed only 25.4 percent in explaining the variance of irrational beliefs. Thus, irrational beliefs cannot be entirely influenced by all of the Big Five personality traits. This is theoretically relevant as it indicates the distinctiveness of irrational beliefs from personality which confirmed the argument of Spörrle et al. (2010) and Jibeen (2015) who opposed the arguments presented by some authors (for example by Zurawski and Smith, 1987) that irrational beliefs can be entirely captured by personality traits or any of its dimensions.

The current findings showed the influence of certain Big Five personality traits on irrational beliefs. This study extended the empirical support concerning the linkages between personality traits and irrationality. This result confirms that neuroticism is positively related to irrational beliefs. On the other hand, extraversion and openness to experience were negatively associated with irrational beliefs.

Considering the evidence on the direct relationship between personality and stress (NewburyBirch \& Kamali, 2001; Constatinos, 2007) and the empirical evidence on the relationship between irrational beliefs and stress (Laura \& María, 2006; Meehan, 2011; Lucica, 2012), there is a reason to introduce the irrational beliefs as a mediator in the relationships between personality traits and stress. This might be attributed to need for further investigation.

However, we also acknowledged some limitations of the present study and the need for further research. Firstly, this study is an initial study on the predictions of the relationship between personality traits and irrational beliefs. Therefore, it cannot be concluded that possessing certain personality traits affects the beliefs of teachers. To investigate the causal relations between the two variables requires the use of an experimental study design. Hence, the experimental design can be carried out in future studies to identify the causal relationships of whether a dependent variable (i.e., irrational beliefs) is actually caused by the manipulation of a particular independent variable (i.e., personality intervention).

Secondly, the study is limited to a sample of primary school teachers in the district of Muar, Johor. Thus, the results may be limited in their generalizibility, for example, to secondary school or private funded schools in Malaysia. Hence, future studies could use a diverse sample, for example teachers from other regions or even other levels in order to gain better understanding of the relationship between personality traits and irrational beliefs among teachers in Malaysia.

Finally, the quantitative survey method also lacked the depth of explanation regarding the irrational beliefs problems of the teachers. Therefore, a separate qualitative research based on the teachers' points of view should employ a case study method to futher understand the irrational belief 
INTERNATIONAL JOURNAL OF ACADEMIC RESEARCH IN BUSINESS AND SOCIAL SCIENCES

Vol. 8, No. 8, August 2018, E-ISSN: 2222-6990 @ 2018 HRMARS

problem among teachers. Qualitative findings may help future researchers to increase their understanding of how each personality trait can influence the irrational thinking of the teachers.

\section{Conclusion}

The present study reveals that personality traits such as neuroticism, openness to experience and extraversion have a unique contribution to the prediction of the irrational beliefs among Malaysian primary school teachers who participated in the research. Specifically, the personality trait of neuroticism makes the most contribution in explaining the irrational beliefs.

These findings illustrate the predictive relationship between personality traits and irrational beliefs. Awareness of this predictive relationship is useful in understanding the importance of Big Five personality traits in explaining the irrational beliefs of teachers. This study uncovers that personality traits such as openness to experience and extraversion generally have a negative influence on irrational beliefs of the teachers. Meanwhile, neuroticism has a positive influence on teachers' irrational beliefs.

The traits significantly predicted their irrational beliefs. In particular, neuroticism has been found to be the strongest predictor of irrational beliefs. Considering the evidence from previous research and the present study, a future study is recommended to replicate these findings with more samples and wider context. This study adds to the literature about REBT which was previously more inclined to discuss the effectiveness of REBT therapy rather than explaining the antecedents or predictive factors of irrational beliefs.

\section{Corresponding Author}

Mastura Mahfar, School of Human Resource Development and Psychology, Universiti Teknologi Malaysia, 81310 Skudai, Johor, Malaysia; E-mail ID: mastura@utm.my

\section{References}

Bakker, A.B., Van der Zee, K.I., Lewig, K.A., \& Dollard, M.F. (2006). The relationship between the big five personality factors and burnout: A study among volunteer counselors. The Journal of Social Psychology, 146, 31-50.

Bermejo-Toro, L. \& Prieto-Ursua, M. (2006). Teachers' irrational beliefs and their relationship to distress in the profession. Psychology in Spain, 16(1), 45-64.

Bernard, M. E. (1990). Taking the stress out of teaching. Melbourne, AUS: Collins-Dove.

Bernard, M. E. (2016). Teacher beliefs and stress. Journal of Rational-Emotive and Cognitive-Behavior Therapy, 34(3), 209-224.

Bernard, M.E., Joyce, M.R., \& Rosenware, P.M. (1983). Helping teachers cope with stress. In A. Ellis \& M.E. Bernard. (Eds.), Rational-emotive approaches to the problems of childhood. (pp. 415466). New York: Plenum Press.

Blau, S., \& Fuller, J. R. (2006). Rational-emotive disputing and the five-factor model: Personality dimensions of the Ellis emotional efficiency inventory. Journal of Rational-Emotive and Cognitive Behavior Therapy, 24(2), 87-100.

Bora, C., Bernard, M. E., Trip, S., Decsei-Radu, A., and Chereji, S. (2009). Teacher irrational belief scalepreliminary norms for Romanian population. Journal of Cognitive and Behavioral Psychotherapies, 9(2), 211-220. 
INTERNATIONAL JOURNAL OF ACADEMIC RESEARCH IN BUSINESS AND SOCIAL SCIENCES

Vol. 8, No. 8, August 2018, E-ISSN: 2222-6990 @ 2018 HRMARS

Brown, C. M., Dowd, E. T., \& Freeman, A. (2010). Rational and irrational beliefs and psychopathology. In D. David, S. J. Lynn, \& A. Ellis (Eds.), Rational and irrational beliefs: Research, theory, and clinical practice (pp. 149-172). New York, NY: Oxford University Press.

Constatinos M. Kokkinos. (2007). Job Stressors, personality and burnout in primary school teachers. British Journal Of Educational Psychology, 77, 229-243.

Costa, P. T., \& McCrae, R. R. (1992). Revised NEO Personality Inventory (NEO-PI-R) and NEO Five Factor Model (NEO-FFI) professional manual. Odessa, FL: Psychological Assessment Resources.

Costa, P.T., \& McCrae, R.R. (1992). Four ways five factors are basic. Personality and Individual Differences, 13, 653-665.

David, D., Montgomery, G. H., Macavie, B., \& Bovbjerg, D. H. (2005). An empirical investigation of Albert Ellis's Binary Model of Distress. Journal of Clinical Psychology, 61(4), 499-516.

Davies, M. F. (2006). Irrational beliefs and unconditional self-acceptance. Correlational evidence linking two key features of REBT. Journal of Rational-Emotive and Cognitive-Behavior Therapy, 24(2), 113-124.

Dewaele, JM., \& Furnham, A. (1999). Extraversion: The unloved variable in applied linguistic research. Language Learning, 49(3), 509-544.

Dryden, W. (1999). Rational emotive behaviour therapy: A personal approach. Bicester, Oxon: Winslow Press Limited.

Dryden, W. (2006). Getting started with REBT: A concise guide for client. New York: Routledge.

Dryden, W. \& Branch, R. (2008). The fundamentals of rational emotive behaviour therapy.

(2nd ed.). New Jersey, USA: John Wiley \& Sons, Ltd.

Ellis, A. (1962). Reason and emotion in psychotherapy. Secaucas, NJ: Citadel Press.

Ellis, A. (1994). Reason and emotion in psychotherapy (2nd ed.). Secaucus, NJ: Birch Lane.

Eswaran, S., Islam, M. A., \& Yusuf, D. H. M. (2011). A study of the relationship between the Big Five personality dimensions and job involvement in a foreign based financial institution in Penang. International Business Research, 4(4), 164-175.

Forman, B. D., \& Forman, S. G. (1978). Irrational beliefs and personality. Journal of Personality Assessment, 42(6), 613-620.

Ghumman, A. \& Shoaib, M. (2013). Personality traits linked with irrational beliefs: A case of adults, Gujrat-Pakistan. Middle-East Journal of Scientific Research, 16(4), 496-501.

Gorman, B. S., \& Simon, W. E. (1977). Personality correlates of rational and irrational beliefs. Rational Living, 12, 25-27.

Jibeen, T. (2015). Personality dimensions and emotional problems: The mediating role of irrational beliefs in Pakistani adult non-clinical. International Journal of Psychology, 50(2), 93-100.

Jones, R. G. (1968). A factored measure of Ellis' irrational belief system with personality and maladjustment correlates. Dissertation Abstracts International, 29, 4379B-4380B.

John, O. P., \& Srivastava, S. (1999). The Big-Five trait taxonomy: History, measurement, and theoretical perspectives. (Vol.2). New York, USA: Guilford Press.

Khoo, H. X. (2015). Irrational Beliefs as mediator in the relationship between activating event and stress among secondary school teachers in Skudai zone. (Unpublished Master Dissertation). Universiti Teknologi Malaysia. Skudai, Johor.

Laura, B. T., \& María, P. U. (2006). Teachers' irrational beliefs and their relationship to distress in the profession. Psychology in Spain, 10(1), 88-96.

Lucica, E. C. (2012). Cognitive and emotional distress evaluation for undergraduate teachers. Social and Behavioural Sciences, 33, 203-207. 
INTERNATIONAL JOURNAL OF ACADEMIC RESEARCH IN BUSINESS AND SOCIAL SCIENCES

Vol. 8, No. 8, August 2018, E-ISSN: 2222-6990 @ 2018 HRMARS

Mahfar, M. (2015). The analysis of validity and reliability of Malaysian teachers irrational beliefs for secondary school teachers. Unpublished Report of Potential Academic Staff (PAS), Research University Grant (RUG). Q.J.130000.2729.00K02. (2012-2013).

McCrae, R. R. \& Costa, P.T., Jr. (1987). Validation of the five-factor model of personality across instruments and observers. Journal of Personality and Social Psychology, 52(1), 81-90.

McCrae, R. R., \& Costa, P. T. (1997). Personality trait structure as a human universal. American Psychologist, 52, 509-516.

McCrae, R. R., \& Costa, P. T., Jr. (2008). Empirical and theoretical status of the five-factor model of personality traits. In G. J. Boyle, G. Matthews, \& D. H. Saklofske (Eds.), The SAGE handbook of personality theory and assessment (Vol. 1, pp. 273-294), Personality theories and models. London, England: SAGE Publications Ltd.

McCrae, R. R., \& John, O. P. (1992). An introduction to the five-factor model and its applications. Journal of Personality, 60, 175-215.

Meehan, K. E. (2011). Examining the relationship between irrational beliefs, rational emotive coping strategies, and teachers burnout. New York: ProQuest.

Newburry-Birch, D. \& F Kamali. (2001). Psychological stress, anxiety, depression, job satisfaction, and personality characteristics in preregistration house officers. Postgrad Med J, 77, 109-111.

Said, N.I.M. (2013). Kepercayaan tidak rasional sebagai perantara antara peristiwa tekanan dan tahap tekanan dalam kalangan guru sekolah berasrama penuh di Johor, Malaysia. (Unpublished Master Dissertation). Universiti Teknologi Malaysia. Skudai, Johor.

Samad, N.I.A., Hashim, Z., Moin, S., \& Abdullah, H. (2010). Assessment of stress and its risk factors among primary school teachers in the Klang Valley, Malaysia. Canadian Center of Science and Education, 2(2), 163-171.

Samar, S. M., Walton, K. E., \& McDermut, W. (2013). Personality traits predict irrational beliefs. Journal of Rational-Emotive and Cognitive-Behavior Therapy, 31, 231-242.

Sava, F. A. (2009). Maldaptive schemas, irrational beliefs, and their relationship with the Five Factor Personality model. Journal of Cognitive and Behavioral Psychotherapies, 9(2), 135-147.

Spörrle, M., \& Strobel, M., \& Tumasjan, A. (2010). On the incremental validity of irrational beliefs to predict subjective well-being while controlling for personality factors. Psicothema, 22(4), 543548.

Sveinsdottir, H., Gunnarsdottir, H., \& Fridriksdottir, H. (2007). Self-assessed occupational health and working environmental of female nurses, cabin crew and teachers. Scandivian Journal of Caring Science, 27, 262-273.

Szentagotai, A. \& Freeman, A. (2007). An analysis of the relationship between irrational beliefs and automatic thoughts in predicting distress. Journal of Cognitive and Behavioral Psychotherapies, 7(1), 1-9.

Tejersen, M.D., \& Kurasaki, R. (2009). Rational emotive behavior therapy: Applications for working with parents and teachers. Estudos de Psicologica (Campinas), 26(1), 3-14.

Trouba, E. J. (2007). A person-organization fit study of the Big Five personality model and attraction to organizations with varying compensation system characteristics. Unpublished Ph.D dissertation. DePaul University, Chicago.

Turner, M. J. \& Barker, J.B. (2015). Examining the effects of rational emotive behavior therapy on the irrational beliefs of blue-chip professionals. Journal of Rational Emotive and CognitiveBehavior Therapy, 33(1), 17-36. 
INTERNATIONAL JOURNAL OF ACADEMIC RESEARCH IN BUSINESS AND SOCIAL SCIENCES

Vol. 8, No. 8, August 2018, E-ISSN: 2222-6990 @ 2018 HRMARS

Vida, N. H. (2010). The effect of personality and coping on perceived work stress among the white collar workforce in Hongkong PGDP. Hongkong.

Warren, J. M. (2013). School counselor consultation: Teacher's experiences with rational emotive behavior therapy. Journal of Rational-Emotive and Cognitive-Behavior Therapy, 31(1), 1-15.

Wicker, F. W., Richardson, F. C., \& Lambert, F. B. (1985). Differential correlates of irrational belief. Journal of Personality Assessment, 49(2), 161-167.

Zingle, H. W, \& Anderson, S. C. (1990). Irrational beliefs and teacher stress. Canadian Journal of Education, 15(4), 445-449.

Zurawski, R.M., \& Smith, T.W. (1987). Assessing irrational beliefs and emotional distress: Evidence and implications of limited discriminant validity. Journal of Counseling Psychology, 34 (2), 224227. 